\section{The Changes of Plasma Amino Acids and Lipid Profiles in Patients with Cystic Fibrosis and Malnutrition induced by Immunonutrition}

\author{
Hloch $\mathrm{O}^{1}$, Fila $\mathrm{L}^{1}$, Havlin $\mathrm{J}^{2}$, Palova $\mathrm{S}^{1}$ and Charvat $\mathrm{J}^{1^{*}}$ \\ ${ }^{1}$ Charles University and Faculty Hospital Prague Motol Department of Internal Medicine and Department of Pneumology, V Úvalu 84, 150 06, Prague 5, Czech Republic \\ ${ }^{2}$ Charles University, 3rd Department of Surgery, and Faculty of Hospital Prague Motol, Czech Republic
}

*Corresponding author: Jiri Charvat, Department of Internal Medicine and Department of Pneumology 2nd Faculty Medicine of Charles University and Faculty Hospital Prague Motol, V Úvalu 84, 150 06, Prague 5, Czech Republic, Tel: +420603280598; E-mail: jiri.charvat@fnmotol.cz

Received date: November 14, 2018; Accepted date: December 01, 2018; Published date: December 10, 2018

Copyright: (C) 2018 Hloch O, et al. This is an open-access article distributed under the terms of the Creative Commons Attribution License, which permits unrestricted use, distribution, and reproduction in any medium, provided the original author and source are credited.

\begin{abstract}
Background: According to the previous report immunonutrition leads to serum amyloid a decline in the cystic fibrosis patients with malnutrition. The goal of the current study was to evaluate the immunonutrition influence on nutrition parameters, plasma amino acid and lipid profiles in cystic fibrosis patients complicated with malnutrition.

Methods: The changes of nutrition parameters and lipid and plasma amino acids profiles induced by immunonutrition and standard nutrition sipping were evaluated in 30 patients with cystic fibrosis in comparison with 55 control healthy subjects.

Results: BMI, plasma prealbumin, transferrin were significantly deteriorated in patients with cystic fibrosis as well as plasma amino acids and lipid profiles in comparison with control subjects. Serum level of triacylgycerols significantly decreased in the cystic fibrosis patients after immunonutrion support. Immunonutrition lead to the elevation of glutamic acid, methionine, arginine and ornithine plasma concentration while the plasma concentration of glutamine, glycine, valine, threonine and tryptophan significantly decreased.
\end{abstract}

Conclusion: Immunonutrition leads to the significant decrease of serum triacylglycerols and to the changes in plasma amino acids profile in the cystic fibrosis patients with malnutrition that may reflect an activation of immune system.

Keywords: Immunonutrition; Cystic fibrosis; Plasma amino acids profile; Lipid profile; Nutrition parameters

\section{Introduction}

Cystic fibrosis is a serious disease with the significant deterioration of the respiratory and gastrointestinal functions. Its management must be oriented to slow down the worsening of the lung functions as well as to relieve the signs of malnutrition. As far as malnutrition negatively influences the patient prognosis the artificial nutrition is indicated in order to improve nutrition status in the patients with cystic fibrosis (CF) $[1,2]$. Immunonutrition can be defined as modulation of the immune system by specific nutrients like arginine or omega3 fatty acids. Recently we reported the sipping of immunonutrition leads to the reduction of serum amyloid A (SAA) but also to the mild increase of serum malonyldialdehyde (MDA) in the patients with cystic fibrosis and malnutrition [3]. We assume these changes may be the result of modification of protein and lipids metabolism due to immunonutrition composition. The aim of the current study was comparison of lipid and plasma amino acids profiles between the patients suffering from CF with malnutrition and healthy subjects and evaluation of the effect of immunonutrition on these parameters.

\section{Patients and Methods}

The study was conducted during the years 2015-2017 in the Department of Internal Medicine. The adult patients suffering from $\mathrm{CF}$ who received, at a minimum, one year of enteral nutrition support took part in study after they provided written informed consent. Control group subjects were selected in order to be comparable regarding age and gender distribution with the patients. The written consent EK-942/13 was obtained from the Ethics Committee of Prague Motol Hospital Faculty, Czech Republic. The protocol complied with the principles in the Helsinki Declaration. Nutridrink (Nutricia Company, Amsterdam, The Netherlands) had been used as a nutrition support administered by sipping before study. BMI was calculated after measuring height and weight of the patient during examination.

Before the start of the immunonutrition application the following examinations were completed: Blood samples for laboratory analyses including albumin, prealbumin, transferrin, lipid profile (Advia 1800, Siemens, Germany) were assessed in the local biochemical and haematology laboratory. All the examinations were taken between 6:30 and 8:30 a.m. after the patient fasted overnight. The concentrations of Plasma amino acids were measured by a high performance chromatogram (HPLC) with a fluorescent detector (Waters, Munich, Germany). Deproteinization was achieved by adding $100 \mu \mathrm{l}$ of $4 \%$ sulphosalicylic acid /Pliva-Lachema, Zagreb, Croatia) with homocystein acid $(18.4 \mathrm{mg} / \mathrm{l})$ to $100 \mu \mathrm{l}$ of plasma. Homocystein acid (Sigma-Aldrich, Prague, Czech Republic) was used as an internal control standard. The sample was mixed and placed in a centrifuge for 5 minutes at $4000 \mathrm{~g}$. Samples were analyzed within 1 week of collection, and the results specified in absolute values (umol/l). After clinical and nutritional parameters were examined the patient changed 
Citation: Hloch O, Fila L, Havlin J, Palova S, Charvat J (2018) The Changes of Plasma Amino Acids and Lipid Profiles in Patients with Cystic Fibrosis and Malnutrition induced by Immunonutrition. J Nutr Disorders Ther 8: 239. doi:10.4172/2161-0509.1000239

Page 2 of 4

from Nutridrink to immunonutrition (Impact Nestle, Vevey, Switzerland) that was given in identical energy amount for the period of 8 weeks.

After 8 weeks all the tests were examined once more and the changes of the parameters were evaluated. The differences between Nutridrink and Impact are shown in Table 1.

\begin{tabular}{|l|l|l|}
\hline & Nutridrink & Impact \\
\hline Protein & $4 \mathrm{gr}(16 \%)$ & $5.6 \mathrm{~g} \mathrm{(22 \% )}$ \\
\hline Sacharides & $12.2 \mathrm{~g} \mathrm{(49 \% )}$ & $\begin{array}{l}13.3 \mathrm{~g} \\
(53 \%)\end{array}$ \\
\hline Fats & $3.9 \mathrm{~g} \mathrm{(35 \% )}$ & $2.8 \mathrm{~g} \mathrm{(25 \% )}$ \\
\hline Fiber & $0.4 \mathrm{~g}$ & $1.0 \mathrm{~g}$ \\
\hline L-Arginine & & $1.27 \mathrm{~g}$ \\
\hline Polyunsaturated fatty acids & & $0.65 \mathrm{~g}$ \\
\hline$\omega^{3}$ polyunsaturated fatty acids & & $0.32 \mathrm{~g}$ \\
\hline
\end{tabular}

Table 1: Comparison of Nutridrink and Impact composition.

\section{Statistical Evaluation}

Numerical values are expressed as mean \pm standard deviation. The normality of the data distribution was evaluated by visual review of histogram and normal probability plot. Parametric continuous data was compared through Student t-tests while non-parametric was compared through Mann-Whitney tests. All the statistical analyses were completed using Statistical 12.0 (Stat Soft, Tulsa, OK).

\section{Results}

\begin{tabular}{|c|c|c|c|}
\hline & Controls & $\begin{array}{l}\text { Cystic fibrosis } \\
\text { on Nutridrink }\end{array}$ & $\begin{array}{l}\text { Cystic } \\
\text { fibrosis on } \\
\text { Impact }\end{array}$ \\
\hline & $n=55$ & $\mathrm{n}=30$ & $\mathrm{n}=30$ \\
\hline $\mathrm{BMI}\left(\mathrm{kg} / \mathrm{m}^{2}\right)$ & $23.5 \pm 2.1$ & $18.8 \pm 1.7^{*}$ & $18.9 \pm 1.6$ \\
\hline Albumin $(\mathrm{g} / \mathrm{L})$ & $43.5 \pm 2.9$ & $45.7 \pm 2.8$ & $45.0 \pm 2.9$ \\
\hline Prealbumin $(\mathrm{g} / \mathrm{L})$ & $0.29 \pm 0.12$ & $0.23 \pm 0.04^{*}$ & $0.22 \pm 0.05$ \\
\hline Transferrin $(\mathrm{g} / \mathrm{L})$ & $3.2 \pm 0.6$ & $2.8 \pm 0.5^{*}$ & $2.7 \pm 0.4$ \\
\hline Total cholesterol (mmol/L) & $4.2 \pm 0.7$ & $3.4 \pm 0.6^{*}$ & $3.3 \pm 0.9$ \\
\hline HDL cholesterol (mmol/L) & $1.3 \pm 0.2$ & $1.1 \pm 0.2^{*}$ & $1.1 \pm 0.2$ \\
\hline LDL cholesterol (mmol/L) & $2.3 \pm 0.4$ & $1.8 \pm 0.2^{*}$ & $1.9 \pm 0.5$ \\
\hline Triacylglycerols (mmol/L) & $1.4 \pm 0.3$ & $1.1 \pm 0.4^{*}$ & $0.9 \pm 0.3^{* \star}$ \\
\hline \multicolumn{4}{|c|}{${ }^{*} \mathrm{P}<0.05$ comparison between controls and cystic fibrosis patients on Nutridrink } \\
\hline \multicolumn{4}{|c|}{$\begin{array}{l}\text { " } P<0.05 \text { comparison between cystic fibrosis patients on Nutridrink and on } \\
\text { Impact }\end{array}$} \\
\hline
\end{tabular}

Table 2: Comparison of the selected nutrition parameters and lipid profile in the patients with cystic fibrosis on Nutridrink and Impact with healthy control subjects.
Thirty patients participated in the study, of which 22 were men and 8 were women and the average age was $24.7 \pm 3.6$ years. Energy intake provided by sipping the drink was $557 \pm 108 \mathrm{kcal}$ daily.

Fifty five healthy control subjects included into study were selected in a way to be comparable with the patients in age and gender distribution, 35 were men and 20 women, the average age was $25.4 \pm$ 3.5 years. No control subjects received any medication.

In Table 2 there are values of the selected nutrition parameters and lipid profile concentration in control subjects in comparison with the changes of lipid profile in the patients with $\mathrm{CF}$.

In Table 3 there are plasma amino acids concentrations in control subjects in comparison with the changes of plasma amino acid profile in the patients with CF.

\begin{tabular}{|c|c|c|c|}
\hline $\begin{array}{l}\text { Amino } \\
\text { (umol/l) }\end{array}$ & Controls & $\begin{array}{l}\text { Cystic fibrosis on } \\
\text { Nutridrink }\end{array}$ & $\begin{array}{l}\text { Cystic fibrosis } \\
\text { on Impact }\end{array}$ \\
\hline & $\mathrm{n}=55$ & $n=30$ & $n=30$ \\
\hline Glutamin acid & $205.9 \pm 56.9$ & $45.2 \pm 20.1^{*}$ & $161.4 \pm 55.0^{* *}$ \\
\hline Asparagine & $42.2 \pm 7.9$ & $34.8 \pm 10.2^{*}$ & $36.9 \pm 6.8$ \\
\hline Serine & $172.5 \pm 53.2$ & $112.7 \pm 27.1^{*}$ & $127.7 \pm 27.9$ \\
\hline Glutamine & $334.7 \pm 53.7$ & $508.2 \pm 87.9^{*}$ & $365.1 \pm 53.5^{* \star}$ \\
\hline Histidine & $89.9 \pm 4.3$ & $80.2 \pm 24.3^{*}$ & $84.5 \pm 11.6$ \\
\hline Glycine & $349.9 \pm 89.8$ & $423.9 \pm 102.6^{*}$ & $286.6 \pm 72.8^{\star *}$ \\
\hline Threonine & $136.4 \pm 51.1$ & $131.9 \pm 35.3$ & $95.1 \pm 28.8^{\star *}$ \\
\hline Citruline & $25.8 \pm 8.6$ & $30.3 \pm 10.9^{*}$ & $27.5 \pm 9.9$ \\
\hline Arginine & $56.1 \pm 7.0$ & $82.5 \pm 20.5^{*}$ & $100.7 \pm 16.5^{\star *}$ \\
\hline Alanine & $296.2 \pm 95.5$ & $344.1 \pm 138.8$ & $311.1 \pm 104.8$ \\
\hline Tyrosine & $83.6 \pm 32.6$ & $57.8 \pm 11.4^{*}$ & $52.3 \pm 17.2$ \\
\hline Valine & $229.3 \pm 47.8$ & $230.1 \pm 44.9$ & $190.1 \pm 39.8^{* *}$ \\
\hline Methionine & $54.6 \pm 18.8$ & $23.0 \pm 5.4^{*}$ & $42.4 \pm 12.5^{* *}$ \\
\hline Tryptophane & $11.5 \pm 5.1$ & $16.8 \pm 7.5^{*}$ & $2.8 \pm 1.0^{* *}$ \\
\hline Phenylalanine & $64.6 \pm 8.0$ & $44.2 \pm 10.3^{*}$ & $43.2 \pm 10.0$ \\
\hline Isoleucine & $77.0 \pm 18.4$ & $63.7 \pm 13.5^{\star}$ & $75.2 \pm 31.3$ \\
\hline Leucine & $148.8 \pm 46.3$ & $98.8 \pm 23.0^{*}$ & $104.8 \pm 30.0$ \\
\hline Ornithine & $75.9 \pm 14.4$ & $61.7 \pm 14.1^{*}$ & $81.3 \pm 40.1^{* *}$ \\
\hline Lysin: e & $194.8 \pm 22.9$ & $150.5 \pm 36.8^{*}$ & $163.6 \pm 66.3$ \\
\hline \multicolumn{4}{|c|}{${ }^{*} \mathrm{P}<0.05$ comparison between controls and cystic fibrosis patients on Nutridrink } \\
\hline $\begin{array}{l}{ }^{* *} \mathrm{P}<0.05 \text { comparis } \\
\text { Impact }\end{array}$ & on between & ic fibrosis patients on & Nutridrink and on \\
\hline
\end{tabular}

Table 3: Comparison of the effect of Nutridrink and Impact on plasma amino acid profile in comparison with healthy subjects.

The patients with CF had significantly lower plasma concentration of glutamic acid, asparagine, serine, histidine, tyrosine, methionine, phenylalanine, leucine, isoleucine, ornithine and lysine. On the other 
side the concentration of glutamine, glycine, citruline, arginine and tryptophan was significantly higher in the patients with CF.

Immunonutrition lead to the elevation of glutamic acid, methionine, arginine and ornithine plasma concentration while the plasma concentration of glutamine, glycine, valine, threonine and tryptophan significantly decreased.

\section{Discussion}

The use of immunonutrition in adult patients with $\mathrm{CF}$ and malnutrition leads to the reduction of serum amyloid A (SAA) and may attenuate inflammation activity [3]. The described changes were associated with the modification of the nutritional support. The application of immunonutriton in comparison with standard nutrition support should be therefore associated with the significant changes also in nutritional and metabolic parameters. The high dosage of some substrates, mainly arginine but also polyunsaturated lipids is applied during immunonutrition support. It was reason why the changes of lipid and amino acids spectrum and nutrition parameters induced by immunonutrition in comparison to routine enteral preparation were compared.

No significant differences were recorded in BMI, serum albumin, prealbumin or transferrin between the application of immunonutrition and sipping of routine enteral formula. It is not surprising as far as the caloric intake and the amount of protein supplementation were not modified.

Serum triacylglycerol concentration decreased significantly from 1.1 $\mathrm{mmol} / \mathrm{l}$ to $0.9 \mathrm{mmol} / \mathrm{L}$. In immunonutrition there is the significant amount of omega 3 fatty acids. It could explain the drop of serum triacylgycerols during Impact application. This may be one of the positive effects of immunonutrition as far as the higher serum triacylglycerols concentration is associated with the risk of development of atherosclerotic changes especially in subjects complicated with diabetes mellitus [4].

The most striking changes are present in plasma amino acids profile. When comparing to healthy control subjects only the concentration of threonine, alanine and arginine was comparable in the patients with $\mathrm{CF}$ and malnutrition receiving nutrition by sipping of routine enteral formula. The concentration of the other amino acids was either significantly higher or lower in comparison to controls.

Arginine represents the basic component of immunonutrition. The elevation of arginine plasma concentration during its application was expected. It may explain the drop of systematic blood pressure described already in our previous study and the increase of cystatin glomerular filtration rate due to arginine vasodilatatory effect [5]. The plasma elevation of ornithine concentration during immunonutrition is the result of arginine metabolism. Ornithine is important in urea production when amino acids turnover is increased [6].

The concentration of glutamic acid and glutamine during the application of immunonutrition was comparable to the ones of healthy controls. It may be explained by activity modulation of enzymes glutaminase and glutamine dehydrogenase. Moreover glutamine can transport ammonium for biosynthesis of purines and other biological compounds and through this way support immune system as a result of immune cells stimulation [7].

Plasma glycine and valine concentration decreased during immunonutrition. Glycine is a forerunner for the formation of numerous essentials biological compounds, such as purines, porphyrins, creatine, gluthatione etc. It is unable to be reused after it is incorporated into most of these compounds, therefore the demand for this amino acid may be greater than the rate it can be synthesized under stressful conditions [8-10]. The branched-chain amino acid valine is a precursor for the protein synthesis and act as regulator of protein turnover [11]. Both amino acids may be more utilized when immune system is stimulated by immunonutrition.

Folllowing surgery of uninfected patients, a decrease sulfur amino acids occurs indicating its retention into tissue components [12]. The similar situations might be present in the malnourished patients with $\mathrm{CF}$ as far as threonine and tryptophan concentration decreased during immunonutrition application.

Threonine is known to assists in antibodies production which are major components of our immune system [13]. Tryptophan is an essential amino acid which should be provided by dietary protein. The degradation of tryptophan into kynurenine by the immune cells plays a pivotal role in the control of immune response during infection and inflammation. Increased tryptofan utilization with following depleted plasma concentration was reported during parasitic, bacterial and viral infections but also in other instances of long-lasting immune activation [14]. CF patients are infected frequently with Pseudomonas aeruginosa in lung tissue. This pathological agent is using tryptophan for its growth using its conversion into kynurenin [15-17]. Local tryptophan depletion could be a mechanism controlling bacteria's proliferation resulting in an arrest of microbial biosynthesis [13].

Contrary the concentration of methionine significantly increased during immunonutrition. This elevation of methionine might be explained by methylation of homocysteine. Unfortunately we are not able to confirm it because homocysteine plasma concentration has not been examined. For the immune system, methionine increases gluthathione, taurine, $\mathrm{CD}^{+}$and $\mathrm{CD}^{+}$cells. It is also important for the initiation of proteosynthesis [18].

The significant changes in plasma amino acids profile in patients with $\mathrm{CF}$ and malnutrition may reflect the activation of the immune system. On the other side the significant decrease of glycine, valine, threonine and tryptophane plasma concentration during the application of immunonutrition may raise the question if the additional amount of these substrates should not be given during such intervention.

\section{Acknowledgments}

This study was supported by Ministry Health of Czech Republic grant-conceptual development of research organisation, 000064203.

\section{References}

1. Pencharz PB, Durie PR (2000) Pathogenesis of malnutrition in cystic fibrosis, and its treatment. Clin Nutr 19: 387-394.

2. Wilson DC, Pencharz PB (1998) Nutrition in cystic fibrosis. Nutrition 14: 792-795.

3. Hloch P, Charvat J, Fila L, Havlin J (2017) Immunonutrition in patients with cystic fibrosis leads to drop of serum amyloid A and increase of oxidative stress. J Clin Bioch Nutrition 60: 176-179.

4. Pirillo A, Catapano AL (2015) Update on the management of severe hypertriglyceridemia-focus on free fatty acid forms of omega-3. Drug Des Devel Ther 9: 2129-2135

5. Vasdev S, Gill V (2008) The antihypertensive effect of arginine. Int J Angiol 17: 7-22. 
Citation: Hloch O, Fila L, Havlin J, Palova S, Charvat J (2018) The Changes of Plasma Amino Acids and Lipid Profiles in Patients with Cystic Fibrosis and Malnutrition induced by Immunonutrition. J Nutr Disorders Ther 8: 239. doi:10.4172/2161-0509.1000239

Page 4 of 4

6. Grasemann H, Schwiertz R, Grasemann C, Vester U, Racké K, et al (2006) Decreased systemic bioavailability of L-arginine in patients with cystic fibrosis. Respir Res 7: 87.

7. Walker MC, der Donk WA (2016) The Many Roles of Glutamate in Metabolism. J Ind Microbiol Biotechnol 43: 419-430.

8. Jahoor F, Badaloo A, Reid M, Forrester T (2006) Glycine production in severe childhood undernutrition. Am J Clin Nutr 84: 143-149.

9. Palova S, Charvat J, Masopust J, Klapkova E, Kvapil M (2007) Changes in the plasma amino acid profile in anorexia nervosa. J Int Med Res 35: 389-394.

10. Jackson AA (1991) The glycine story. Eur J Clin Nutr 45: 59-65.

11. Boirie Y, Gachon P, Beaufrere B (1997) Splanchnic and whole-body leucine kinetics in young and elderly men. Am J Clin Nutr 65: 489-495.

12. Grimble RF, Grimble GK (1998) Immunonutrition: Role of Sulfur Amino Acids, Related Amino Acids, and Polyamines. Nutrition 14: 605-610.

13. Grimble RF (2006) The Effects of Sulfur Amino Acid Intake on Immune Function in Human. J Nutr 136: 1660S-1665S.
14. Le Floch N, Otten W, Merlot E (2011) Tryptophan metabolism, from nutrition to potential therapeutic applications. Amino Acids 41: 1195-1205.

15. Genestet CH, Le Goullec A, Chaker H, Polack B, Guery B, et al. (2014) Scavenging of reactive oxygen species by tryptophan metabolites helps Pseudomonas aeruginosa escape neutrophile killing. J Free Rad Biomed 73: 400-410.

16. Palmer GC, Jorth PA, Whiteley M (2013) The role of two Pseudomonas aeruginosa anthranilate synthases in tryptophan and quorum signal production. Microbiology 159: 959-969.

17. Easther CHR, Coakley RD, Henderson AG, Zhou YH, Wright FA, et al. (2015) Metabolomic Evaluation of Neutrophilic Airway Inflammation in Cystic Fibrosis, CHEST 148: 507-515.

18. Alshaikh B, Dchall JI, Maqbool A, Mascarenhas M, Bennett MJ, et al. (2016) Choline supplementation alters some amino acid concentrations with no change in homocysteine in children with cystic fibrosis and pancreatic insufficiency. Nutrition Research 36: 418-429. 